\title{
Synthesis of Crosslinked Polystyrene-b-Poly(hydroxyethyl methacrylate)-b- Poly(styrene sulfonic acid) Triblock Copolymer for Electrolyte Membranes
}

\author{
Do Kyoung Lee, Jung Tae Park, Dong Kyu Roh, Byoung Ryul Min, and Jong Hak Kim* \\ Department of Chemical and Biomolecular Engineering, Yonsei University, Seoul 120-749, Korea
}

Received August 5, 2008; Revised October 30, 2008; Accepted October 31, 2008

\begin{abstract}
The synthesis and the characterization of crosslinked ABC triblock copolymer, i.e. polystyrene- $b$-poly (hydroxyethyl methacrylate)- $b$-poly(styrene sulfonic acid), (PS- $b$-PHEMA- $b$-PSSA) is reported. PS- $b$-PHEMA- $b$ PSSA triblock copolymer at 20:10:70 wt\% was sequentially synthesized via atom transfer radical polymerization (ATRP). The middle block was crosslinked by sulfosuccinic acid (SA) via the esterification reaction between -OH of PHEMA and -COOH of SA, as demonstrated by FTIR spectroscopy. As increasing amounts of SA, ion exchange capacity (IEC) continuously increased from 2.13 to $2.82 \mathrm{meq} / \mathrm{g}$ but water uptake decreased from 181.8 to $82.7 \%$, resulting from the competitive effect between crosslinked structure and the increasing concentration of sulfonic acid group. A maximum proton conductivity of crosslinked triblock copolymer membrane at room temperature reached up to $0.198 \mathrm{~S} / \mathrm{cm}$ at $3.8 \mathrm{w} \%$ of SA, which was more than two-fold higher than that of Nafion $117(0.08 \mathrm{~S} / \mathrm{cm})$. Transmission electron microscopy (TEM) analysis clearly showed that the PS- $b$-PHEMA- $b$-PSSA triblock copolymer is microphase-separated with a nanometer range and well developed to provide the connectivity of ionic PSSA domains. The membranes exhibited the good thermal properties up to $250{ }^{\circ} \mathrm{C}$ presumably resulting from the microphase-separated and crosslinked structure of the membranes, as revealed by thermal gravimetric analysis (TGA).
\end{abstract}

Keywords: proton conductivity, ATRP, membrane, crosslinked, block copolymer.

\section{Introduction}

During the past decades, polymer electrolytes have received much attention due to their significant technological use as ion-exchange resins, electrodialysis, bipolar membranes, sensors, and lithium batteries. ${ }^{1,2}$ Especially, sulfonated polymer membranes have been extensively investigated for the applications to fuel cells, as can be seen from the increasing number of research papers. ${ }^{3-9}$ The commercially available membranes in fuel cells are mostly based on perfluorosulfonic polymers such as Nafion, Gore-Select, Aciplex, Xus and Flemiom. They exhibited the excellent thermal and mechanical properties as well as high proton conductivity (around $0.1 \mathrm{~S} / \mathrm{cm}$ at room temperature). However perfluorosulfonic polymers have some limitations such as high methanol permeability and high cost. Therefore, there has been a great deal of research into alternative sulfonated polymeric materials..$^{3-9}$

A high proton conductivity of sulfonated polymer membranes has been considered essential to improve the efficiency of fuel cells. The sulfonated polymers with high degree of sulfonation exhibit high proton conductivity but

*Corresponding Author. E-mail: jonghak@yonsei.ac.kr typically produce water solubility, leading to their inadequate use for fuel cells or other applications. Thus, crosslinking has been used as a good solution to maintain a proper sulfonation level and to enhance the mechanical properties. ${ }^{10-12}$ There have been many attempts to develop crosslinked sulfonated polymer membranes using polyimide, ${ }^{13}$ poly(vinyl alcohol), ${ }^{14}$ and poly(2,6-dimethyl-1,4-phenylene oxide). ${ }^{15}$

Use of self-organized, nanophase-separated structure can allow for a better control of both the sulfonation degree and the distribution of sulfonic acid groups in the sulfonated polymer membranes. Among them, block copolymers consisting of more than two domains with different chemical properties are considered to offer an effective approach for incorporating higher ionic properties into a material while retaining desirable mechanical properties of the polymer. ${ }^{11,16-18}$ The advantages of the use of microphase-separated block copolymers are as follows; 1) controlling of the swelling of the ion conducting domains by the surrounding non-conducting domains, 2) lowering of the methanol permeability due to decreased swelling, and 3) high mechanical stability due to the inert matrix of nonsulfonated segments.

In the present study, we report on the crosslinked, protonconductive polymer electrolyte membranes consisting of ABC triblock copolymer, i.e. polystyrene- $b$-poly(hydroxyethyl 
methacrylate)- $b$-poly(styrene sulfonic acid), (PS- $b$-PHEMA$b$-PSSA) at 20:10:70 wt $\%$ synthesized via atom transfer radical polymerization (ATRP). ${ }^{19,20}$ A hydrophobic PS block acts as a nonconducting domain and a hydrophilic PSSA block works as a conducting domain. A middle PHEMA block is used for crosslinking reaction with sulfosuccinic acid (SA) via the esterification reaction between - $\mathrm{OH}$ of PHEMA and -COOH of SA. The detailed properties of ion exchange capacity (IEC), water uptake, proton conductivity, morphology and the thermal properties of membranes are reported.

\section{Experimental}

Materials. Styrene (99\%), 2-hydroxyethyl methacrylate (HEMA, 99\%), 4-styrenesulfonic acid sodium salt hydrate (SSA), 1,1,4,7,10,10-hexamethyltriethylenetetramine (HMTETA, 99\%), copper(I) chloride (CuCl, 99\%), methyl 2-bromopropionate (MBP) and sulfosuccinic acid (70 wt\% in water) were purchased from Aldrich and used as received without further purification.

Synthesis of PS-Br Macroinitiator. In a $250 \mathrm{~mL}$ pearshaped flask, $20 \mathrm{~g}$ of styrene, $0.296 \mathrm{~g}$ of $\mathrm{CuCl}$ and $1.24 \mathrm{~mL}$ of HMTETA were added and then the green mixture was stirred until homogeneous solution. Nitrogen was purged to the solution for $30 \mathrm{~min}$, and then $0.22 \mathrm{~mL}$ of MBP was added. The mixture was placed in a $110^{\circ} \mathrm{C}$ oil bath for $5 \mathrm{~h}$. After polymerization, the resultant polymer was diluted with THF. After passing the solution through a column with activated $\mathrm{Al}_{2} \mathrm{O}_{3}$ to remove the catalyst, and precipitated into methanol. PS-Br macroinitiator was obtained and dried in a vacuum oven overnight at room temperature.

Synthesis of PS-b-PHEMA Diblock Copolymer. In a $250 \mathrm{~mL}$ pearshaped flask, $6 \mathrm{~g}$ of PS-Br was dissolved in $10 \mathrm{~mL}$ of toluene with stirring. $4 \mathrm{~mL}$ of HEMA, $0.0888 \mathrm{~g}$ of $\mathrm{CuCl}$ and $0.372 \mathrm{~mL}$ of HMTETA were added to the solution. The green mixture was stirred until homogeneous solution and purged with nitrogen for $30 \mathrm{~min}$. The mixture was placed in a $50^{\circ} \mathrm{C}$ oil bath for $7 \mathrm{~h}$. After polymerization, the resultant block copolymer was diluted with THF. After passing the solution through a column with activated $\mathrm{Al}_{2} \mathrm{O}_{3}$ to remove the catalyst, and precipitated into methanol. PS$b$-PHEMA diblock copolymer was obtained and dried in a vacuum oven overnight at room temperature.

Synthesis of PS- $b$-PHEMA-b-PSSA Triblock Copolymer. In a $250 \mathrm{~mL}$ pearshaped flask, $5 \mathrm{~g}$ of PS- $b$-PHEMA was dissolved in $60 \mathrm{~mL}$ of NMP with stirring. $15 \mathrm{~g}$ of SSA dissolved in $50 \mathrm{~mL}$ of DMSO was added into the flask. $0.074 \mathrm{~g}$ of $\mathrm{CuCl}$ and $0.31 \mathrm{~mL}$ of HMTETA were added to the solution. The green mixture was stirred until homogeneous solution and purged with nitrogen for $30 \mathrm{~min}$. The mixture was placed in a $110^{\circ} \mathrm{C}$ oil bath for $24 \mathrm{~h}$. After passing the solution through a column with activated $\mathrm{Al}_{2} \mathrm{O}_{3}$ to remove the catalyst, and precipitated into methanol. PS- $b$ -
PHEMA- $b$-PSSA triblock copolymer was obtained and dried in a vacuum oven overnight at room temperature.

Preparation of Crosslinked Triblock Copolymer Membrane. $1 \mathrm{~g}$ of the PS- $b$-PHEMA- $b$-PSSA triblock copolymer was dissolved in $20 \mathrm{~mL}$ of DMSO with stirring. Different amounts of SA were added into the solution and stirred for more than $2 \mathrm{~h}$. The mixtures were cast on a glass dish, and dried at room temperature overnight and in an oven at $80^{\circ} \mathrm{C}$ for two days. The obtained membranes were peeled off from the dishes and then annealed at $120^{\circ} \mathrm{C}$ for $3 \mathrm{~h}$ for crosslinking reaction. The membranes were washed with water several times to remove unreacted SA.

Ion Exchange Capacity (IEC). IEC of the membranes was measured by the classical titration method. The membranes were soaked in $1.0 \mathrm{M} \mathrm{NaCl}$ solution for $24 \mathrm{~h}$ before measuring IEC. The protons released due to the exchange reaction with $\mathrm{Na}$ ions were titrated against $0.01 \mathrm{M}$ standardized $\mathrm{NaOH}$ solution, using phenolphthalein indicator. The IEC of the membranes was calculated using the following equation.

$$
\operatorname{IEC}(\mathrm{mEq} / \mathrm{g})=\frac{X \times N_{\mathrm{NaOH}}}{\text { Weight }(\text { polymer })}
$$

where $X$ is the volume of $\mathrm{NaOH}$ consumed and $N_{\mathrm{NaOH}}$ is the normality of $\mathrm{NaOH}$.

Water Uptake. Water uptake was determined by weighing vacuum dried membrane and fully equilibrated membrane with water. The surface of the membrane sample was quickly wiped with an absorbent paper to remove the excess of water adhering to it and the sample was then weighed. The water uptake of the membrane was determined from

$$
\text { Water Uptake }(\mathrm{wt} \%)=\frac{W_{\mathrm{w}}-W_{d}}{W_{d}} \times 100
$$

where $W_{w}$ and $W_{d}$ are the weights of wet and dried membranes, respectively.

Proton Conductivity. A four-point probe method was used to measure the proton conductivity of the membranes. Before the measurement of proton conductivity, the prepared membranes were equilibrated with deionized water. Complex impedance measurements were carried out in the frequency range $1 \mathrm{~Hz}-8 \mathrm{MHz}$ at $25^{\circ} \mathrm{C}$, using a ZAHNER IM-6 impedance analyzer. The impedance spectra of the membranes can be used to generate Nyquist plots, and the proton conductivity was calculated from the plots.

Characterization. ${ }^{1} \mathrm{H}$ NMR spectra were obtained on a Bruker AV400 NMR spectrometer (400 MHz) using $\mathrm{CDCl}_{3}$ as solvent and tetramethylsilane (TMS) as the internal reference. FTIR spectra were recorded using a Nicolet (MagnaIR 560) spectrometer equipped with ATR (Thunder domeHATR). For TEM measurements, the dried film was ionexchanged with $1 \mathrm{M} \mathrm{AgNO}_{3}$ aqueous solution. The film was dissolved in DMSO, and then a drop of this solution was placed onto a standard copper grid. TEM picture was obtained 
from a Philips CM30 microscope operating at $300 \mathrm{kV}$. The thermal properties of the copolymer membranes were determined by thermal gravimetric analysis (TGA, Mettler Toledo TGA/SDTA 851e, Columbus, OH). TGA measurements were performed from room temperature to $500{ }^{\circ} \mathrm{C}$ at a rate of $20^{\circ} \mathrm{C} / \mathrm{min}$. The amounts of the membranes were determined as a weight loss percentage during heating.

\section{Results and Discussion}

The synthetic procedures of crosslinked PS- $b$-PHEMA- $b$ PSSA membranes are presented in Scheme I. First, the homopolymerization of styrene in bulk initiated by MBP/ $\mathrm{CuCl} / \mathrm{HMTETA}$ was carried out at $110^{\circ} \mathrm{C}$ for $5 \mathrm{~h}$. The obtained PS achieved a narrow molecular distribution (PDI $=1.3$ ) and the molecular weight of $14,000 \mathrm{~g} / \mathrm{mol}$, determined from GPC. The yield of polymerization was as high as $90 \%$. PS- $b$-PHEMA diblock copolymer was then synthesized using $\mathrm{PS}-\mathrm{Br}$ as a macroinitiator and $\mathrm{CuCl} / \mathrm{HMTETA}$. The resulting diblock copolymer exhibited a narrow molecular distribution (PDI=1.4) and the molecular weight of 19,000 g/mol. A solution polymerization with cosolvent, i.e. NMP and DMSO was performed to produce PS- $b$-PHEMA- $b$-PSSA triblock copolymer. It is noted that PS- $b$-PHEMA and SSA should be separately dissolved in NMP and DMSO, respectively, and then combined together to produce a homogenous solution. The resultant PS- $b$-PHEMA- $b$-PSSA triblock copolymer was only soluble in highly polar solvent such as DMSO because of the high concentration of PSSA (70\% from NMR) in the triblock copolymer.

The triblock copolymer was crosslinked with SA via the esterification between -OH of PHEMA and -COOH of SA. Since SA also contains sulfonic acid group, crosslinked middle block becomes conducting domains. Thus the crosslinked triblock copolymer consists of hydrophobic nonconducting PS block, crosslinked conducting PHEMA block and hydrophilic conducting PSSA block. Upon crosslinking reaction at $120^{\circ} \mathrm{C}$ for $3 \mathrm{~h}$, the membranes were washed with water several times to remove unreacted SA. As a result, the reacted SA concentrations were measured by the weight change of membranes. The results are presented in Table I, comparing the added SA concentrations with the actual concentrations.

The chemical structure and the composition of triblock copolymer were confirmed by ${ }^{1} \mathrm{H}$ NMR spectroscopy. Figure 1 shows the ${ }^{1} \mathrm{H}$ NMR spectrum of PS- $b$-PHEMA- $b$-PSSA triblock copolymer. The signals of (a) at 7.5 and (b) $7.0 \mathrm{ppm}$ are attributed to benzene groups of PSSA and PS, respectively. The signals of (e, d, f) at 4.8, 3.9 and 3.5 ppm result

Table I. The Actual and Added SA Concentrations in PS-bPHEMA-b-PSSA Membranes

\begin{tabular}{llll}
\hline Added SA Concentration & $3.8 \mathrm{wt} \%$ & $7.6 \mathrm{wt} \%$ & $15.0 \mathrm{wt} \%$ \\
\hline Actual SA Concentration & $3.1 \mathrm{wt} \%$ & $6.9 \mathrm{wt} \%$ & $13.5 \mathrm{wt} \%$ \\
\hline
\end{tabular}

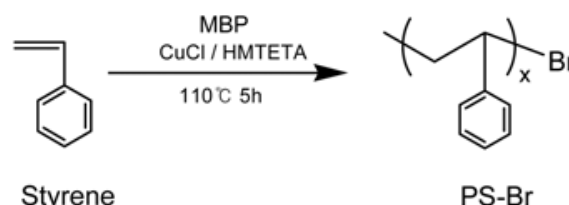

Styrene

$\mathrm{PS}-\mathrm{Br}$

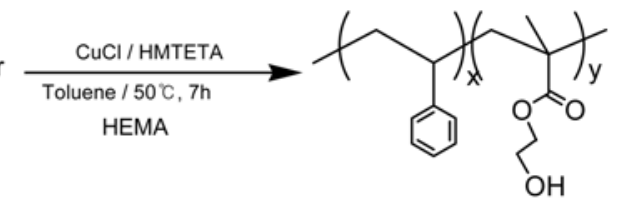

PS- $b$-PHEMA-Br

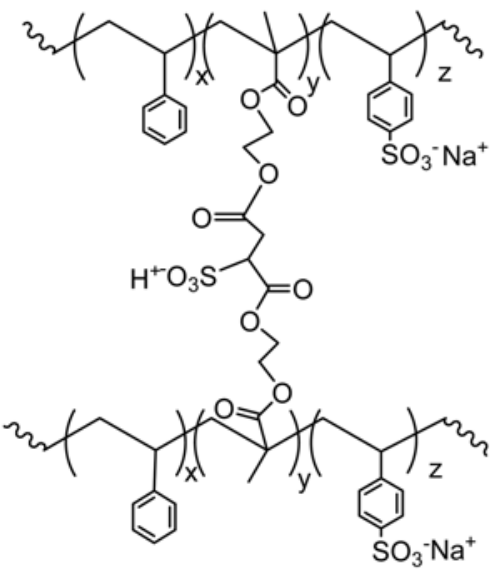

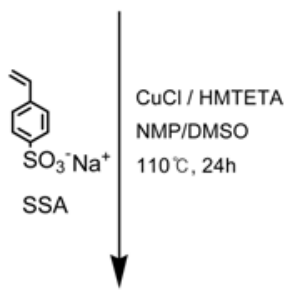

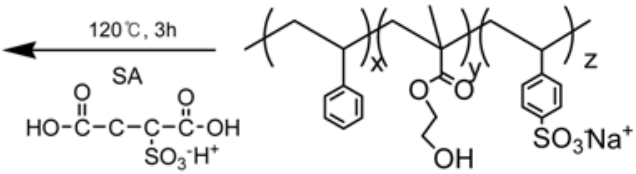

PS- $b$-PHEMA- $b$-PSSA

Crosslinked PS- $b$-PHEMA- $b$-PSSA

Scheme I. Synthetic procedures of crosslinked PS- $b$-PHEMA- $b$-PSSA membranes. 


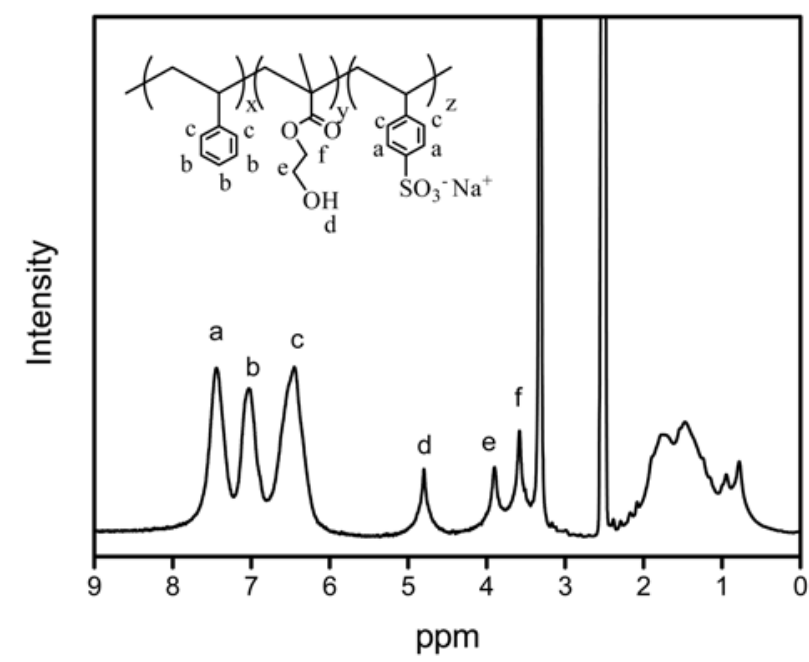

Figure 1. ${ }^{1} \mathrm{H}$ NMR spectrum of PS- $b$-PHEMA- $b$-PSSA triblock copolymer.

from the middle block PHEMA. The ${ }^{1} \mathrm{H}$ NMR spectrum presents that the triblock copolymer has a composition of 20:10:70 wt $\%$ in PS- $b$-PHEMA- $b$-PSSA and the synthesis via ATRP is successful.

Figure 2(a) presents the FTIR spectra of PS homopolymer, PS- $b$-PHEMA diblock copolymer and PS- $b$-PHEMA- $b$ PSSA triblock copolymer synthesized by ATRP. The aromatic $\mathrm{C}=\mathrm{C}$ stretching modes of neat PS produced four peaks at $1601,1583,1494$ and $1451 \mathrm{~cm}^{-1} .{ }^{21}$ Upon diblock copolymerization, the new stretching bands appeared at 3432, 1720 and $1156 \mathrm{~cm}^{-1}$, assigned to $-\mathrm{OH},-\mathrm{C}=\mathrm{O}$ and $\mathrm{C}-\mathrm{O}$ of PHEMA, respectively. PS- $b$-PHEMA- $b$-PSSA triblock copolymer exhibited the absorption bands at 3434, 1642, 1180 and $1036 \mathrm{~cm}^{-1}$. The former two peaks are attributed to the water bounded to ionic group whereas the latter two peaks are due to the stretching vibrations of the sulfonic acid of PSSA with a sodium form. These FTIR spectroscopic results are clear evidence of the sequential synthesis of triblock copolymer by ATRP.

Figure 2(b) shows the FTIR spectra of the crosslinked PS- $b$-PHEMA- $b$-PSSA membranes with SA at $120^{\circ} \mathrm{C}$ for $3 \mathrm{~h}$. The pristine uncrosslinked PS- $b$-PHEMA- $b$-PSSA exhibited the stretching bands at 3434 and $1180 \mathrm{~cm}^{-1}$, attributed to -OH of the water mostly bounded to PSSA and the sulfonic group with a sodium form. With increasing amounts of SA, the stretching band of -OH became asymmetric with a shift of main peak position to $3398 \mathrm{~cm}^{-1}$. It may be due to the fact that SA contains the sulfonic group with an acid form, providing stronger hydrogen bonded -OH in water compared to the sulfonic group with a sodium form in PSSA. ${ }^{22}$ The stronger hydrogen bonding interaction, the lower wavenumber the stretching band appears at. Because of the different form of sulfonic acid group in SA from PSSA, the crosslinked triblock copolymer exhibited the stretching band at a higher wavernumber of $1218 \mathrm{~cm}^{-1}$
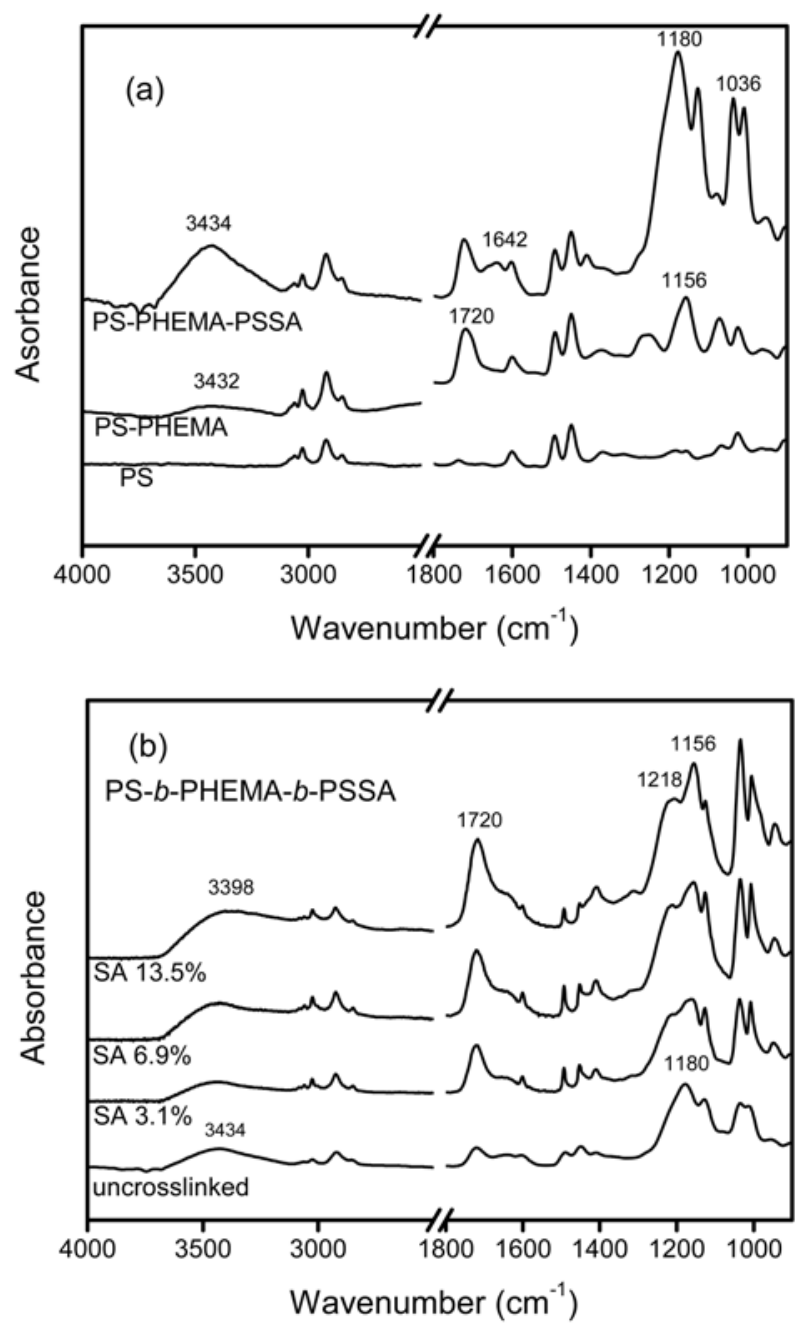

Figure 2. (a) FTIR spectra of PS, PS- $b$-PHEMA and PS- $b$ PHEMA- $b$-PSSA; (b) FTIR spectra of the crosslinked PS- $b$ PHEMA- $b$-PSSA membranes with SA at $120^{\circ} \mathrm{C}$ for $3 \mathrm{~h}$.

for sulfonic group. Upon the introduction of SA, two stretching bands at 1720 and $1156 \mathrm{~cm}^{-1}$ grew up noticeably, resulting from $-\mathrm{C}=\mathrm{O}$ and $\mathrm{C}-\mathrm{O}$ in the ester bond, respectively. ${ }^{23}$ These FTIR spectroscopic results are a clear evidence of a crosslinking reaction by the esterification between - $\mathrm{OH}$ of PHEMA and -COOH of SA.

The IEC value represents the quotient of the molar content of sulfonic acid groups to membrane weight. The IEC data of PS- $b$-PHEMA- $b$-PSSA triblock copolymer membranes crosslinked with the different amounts of SA are presented in Figure 3. As expected, the IEC values continuously increased from 2.13 to $2.82 \mathrm{meq} / \mathrm{g}$ with increasing amounts of SA, mostly due to the increasing portion of charged groups in the membrane. It should be noted that the SA also contains a negative charged fix ion, i.e. sulfonic acid group. All the membranes exhibited much higher IEC values than that of Nafion 117. Higher IEC values of the crosslinked triblock copolymer demonstrate that the higher amounts of 


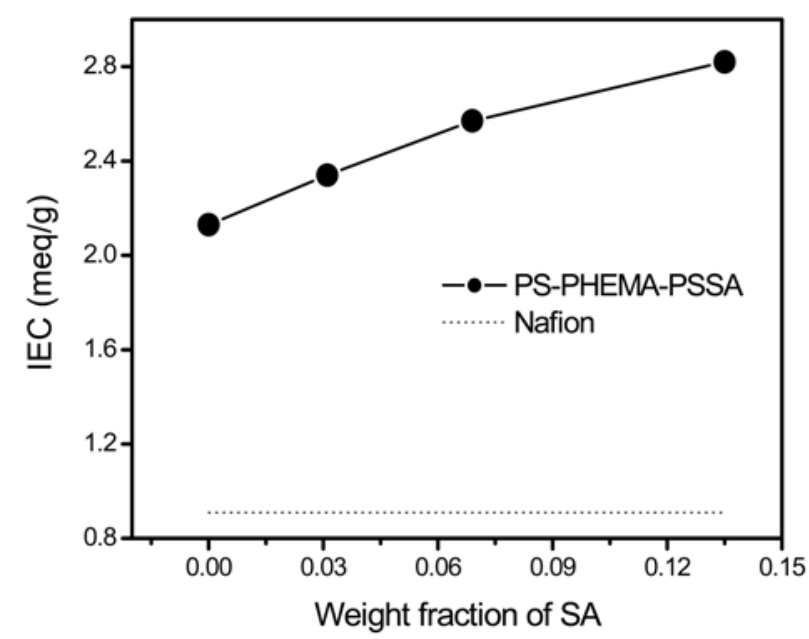

Figure 3. IEC of crosslinked PS- $b$-PHEMA- $b$-PSSA membranes with different amounts of SA.

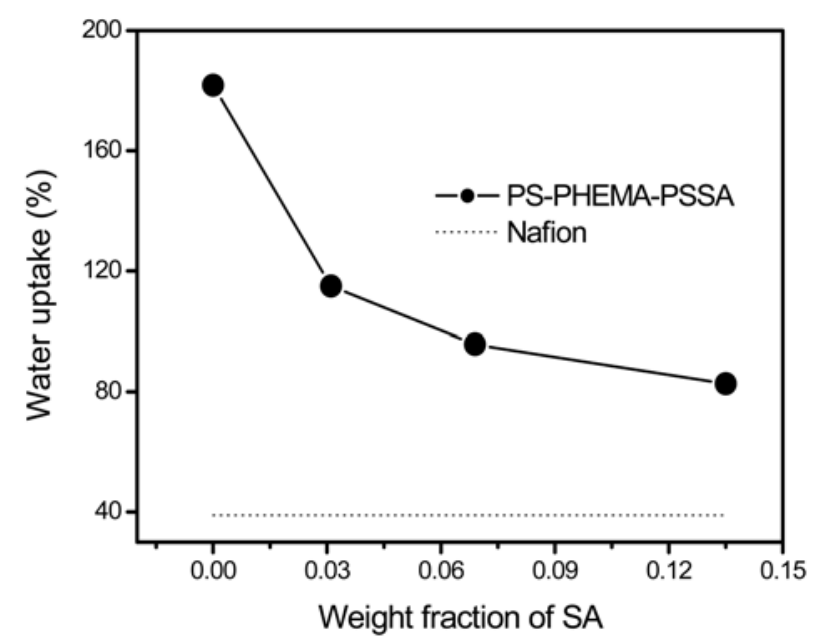

Figure 4. Water uptake of crosslinked PS- $b$-PHEMA- $b$-PSSA membranes with different amounts of SA.

sulfonic aicd groups are contained in the membranes.

Figure 4 presents the water uptake of PS- $b$-PHEMA- $b$ PSSA triblock copolymer membranes crosslinked with the different amounts of SA. A water uptake may be related to the concentration of ionic sites, i.e., sulfonic acid groups. However, the water uptake continuously decreased from 181.8 to $82.7 \%$ with increasing amounts of SA even though the concentration of sulfonic acid group (IEC value) continuously increased with the SA contents as shown in Figure 3. It is attributable to the fact that the introduction of SA produces the crosslinking of triblock copolymer, leading to more rigid and compact structure of membrane.

The proton conductivities of crosslinked PS- $b$-PHEMA$b$-PSSA triblock copolymer membranes with the different amounts of SA are given in Figure 5. The proton conductivities of crosslinked triblock copolymer membranes were in the range of $10^{-2}$ to $10^{-1} \mathrm{~S} / \mathrm{cm}$ at room temperature. Higher

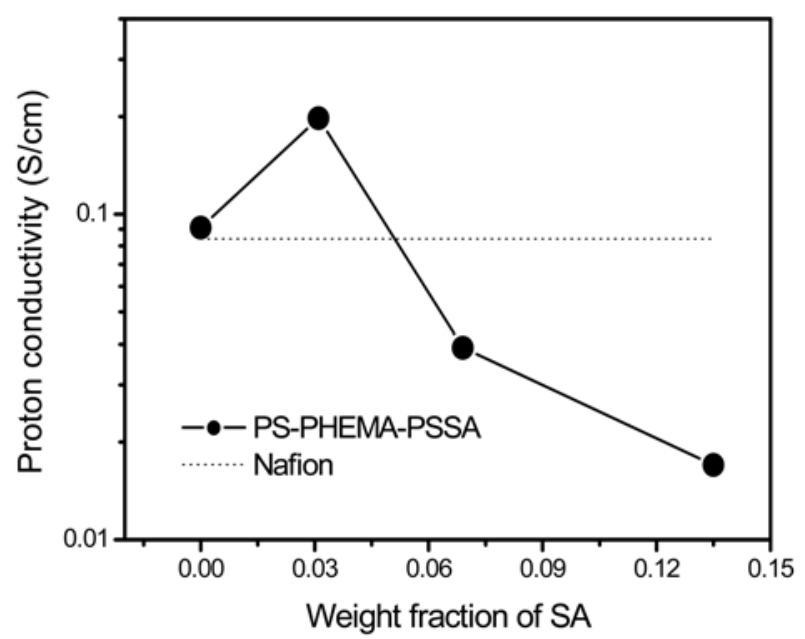

Figure 5. Proton conductivity of the crosslinked PS- $b$-PHEMA$b$-PSSA membranes with different amounts of SA.

conductivities of the crosslinked triblock copolymer membranes probably result from higher values of IEC in the membranes. It should be noted that the IEC values of membranes are as high as 2.13-2.82 but the membranes are not soluble in water. This might be originated from the nanophase separated and crosslinked structure of the membranes. It is generally known that proton conductivities are significantly dependent upon the contents of acidic $\mathrm{SO}_{3}^{-}$groups or IEC values. However, the proton conductivity was not continuously increased with SA contents but a maximum conductivity of $0.198 \mathrm{~S} / \mathrm{cm}$ was achieved at $3.1 \mathrm{wt} \%$. This result is again related to the fact that the membranes become more rigid and compact due to crosslinking reaction with increasing concentrations of SA in the membranes.

TEM analysis was carried out to observe the microphaseseparated structure of PS- $b$-PHEMA- $b$-PSSA triblock

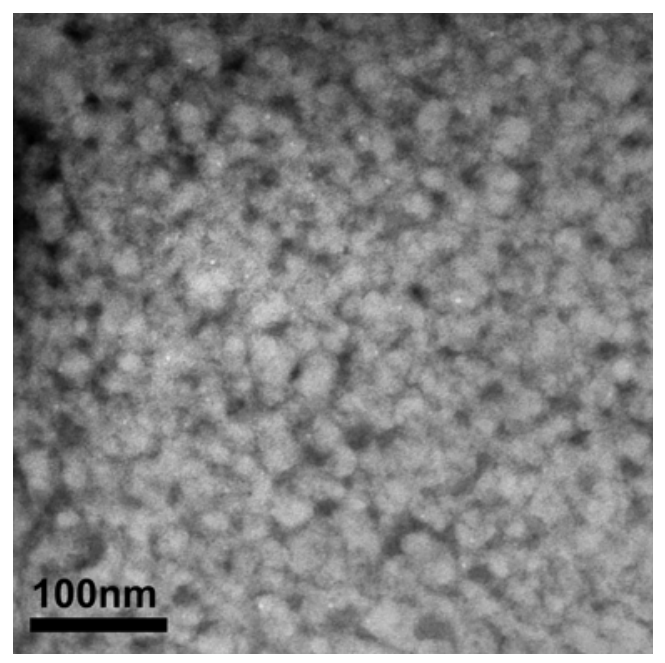

Figure 6. TEM picture of PS- $b$-PHEMA- $b$-PSSA triblock copolymer electrolyte. 


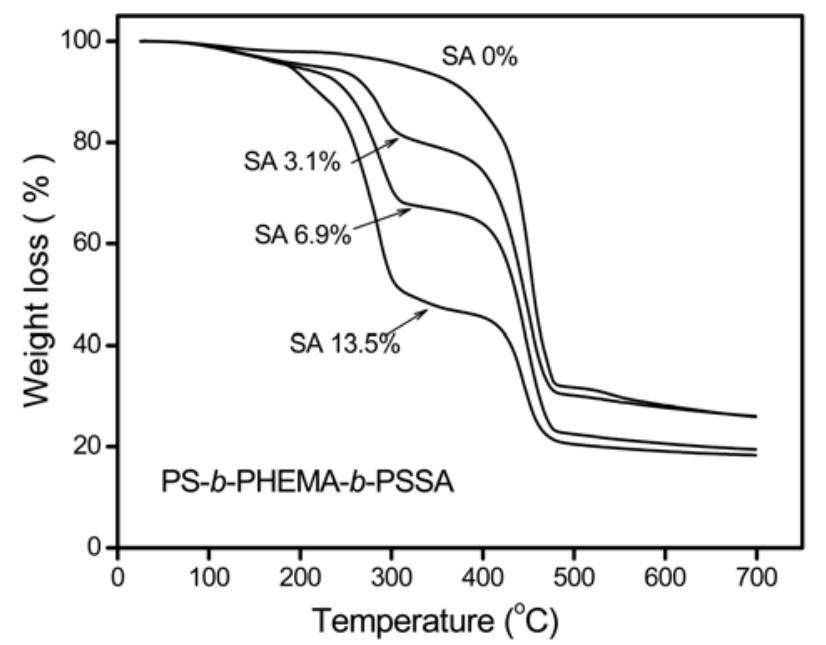

Figure 7. TGA data of PS- $b$-PHEMA- $b$-PSSA triblock copolymer membranes crosslinked with the different amounts of SA.

copolymer. Figure 6 presents the TEM image of pristine triblock copolymer. The dark regions are presumably assigned to the PSSA domains of ionic $\mathrm{SO}_{3} \mathrm{Na}$ aggregates whereas the bright regions are attributable to PS and PHEMA domains. This TEM picture clearly shows that the PS- $b$-PHEMA- $b$-PSSA triblock copolymer is microphaseseparated with a nanometer range and well developed to provide the connectivity of ionic PSSA domains. This morphology may be responsible for the high proton conductivity of triblock copolymer membranes..$^{24,25}$

The thermal stabilities of pristine and crosslinked PS- $b$ PHEMA- $b$-PSSA triblock copolymer membranes were investigated by TGA as shown in Figure 7. The first slight weight loss for all membranes was observed around $100{ }^{\circ} \mathrm{C}$, attributed to the loss of adsorbed water by the hygroscopic property of the membrane. The pristine triblock copolymer exhibited excellent thermal stability up to $400{ }^{\circ} \mathrm{C}$. However, the degradation of the crosslinked triblock copolymer exhibited two steps in the region of 250 and $450^{\circ} \mathrm{C}$, which became more prominent with the increase of SA amounts. Generally, the membranes with higher crosslinking density exhibits more stable thermal stability. In our results, however, the copolymer membrane crosslinked with SA $13.5 \mathrm{wt} \%$ unexpectedly exhibited lower thermal stability than that with SA 0 wt\%. This unexpected result is likely due to the lower thermal stability of the ester groups in SA compared with the backbones in triblock copolymer. The TGA data represent that the effect of crosslinking on the thermal stability of the membranes was not significantly pronounced but all membranes were quite thermally stable below $250^{\circ} \mathrm{C}$.

\section{Conclusions}

The highly proton conducting materials were developed by synthesizing PS- $b$-PHEMA- $b$-PSSA triblock copolymer at 20:10:70 wt\% through ATRP, followed by the crosslinking of middle PHEMA block with SA. The measured proton conductivity of the membranes reached up to around 0.2 $\mathrm{S} / \mathrm{cm}$ at $3.1 \mathrm{wt} \%$ of SA, which was at least two times higher than that of the Nafion 117 membrane under comparable conditions. The excellent proton conductivities but the waterinsoluble properties of the membranes are presumably related to higher IEC values of 2.13-2.82 meq/g and the crosslinked nanophase separated structure of the membranes. The characterization of the membranes by TGA also demonstrated their high thermal stability up to $250{ }^{\circ} \mathrm{C}$.

Acknowledgement. This work was supported by the Korea Science and Engineering Foundation (KOSEF) grant funded by the government (MEST) (R01-2008-000-10112-0) and the Ministry of Knowledge Economy (MKE) and Korea Industrial Technology Foundation (KOTEF) through the Human Resource Training Project for Strategic Technology.

\section{References}

(1) N. Venkatasubramanian, D. R. Dean, G. E. Price, and F. E. Arnold, High Perform. Polym., 9, 291 (1997).

(2) W. J. Lee and S. H. Kim, Macromol. Res., 16, 247 (2008).

(3) R. T. S. M. Lakshmi, J. Meier-Haack, K. Schlenstedt, H. Komber, V. Choudhary, and I. K.Varma, React. Funct. Polym., 66, 634 (2006).

(4) B. Liu, G. P. Robertson, M. D. Guiver, Z. Shi, T. Navessin, and S. Holdcroft, Macromol. Rapid Commun., 27, 1411 (2006).

(5) J. Won, S. M. Ahn, H. D. Cho, J. Y. Ryu, H. Y. Ha, and Y. S. Kang, Macromol. Res., 15, 459 (2007).

(6) R. T. S. M. Lakshmi, M. K. Vyas, A. S. Brar, and I. K. Varma, Eur. Polym. J., 42, 1423 (2006).

(7) J. Li, C. H. Lee, H. B. Park, and Y. M. Lee, Macromol. Res., 14, 438 (2006).

(8) H. J. Kim, M. H. Litt, S. Y. Nam, and E. M. Shin, Macromol. Res., 11, 458 (2003).

(9) D. S. Kim, M. D. Guiver, M. Y. Seo, H. I. Cho, D. H. Kim, J. W. Rhim, G. Y. Moon, and S. Y. Nam, Macromol. Res., 15, 412 (2007).

(10) J. H. Son, Y. S. Kang, and J. Won, J. Membr. Sci., 281, 345 (2006).

(11) J. Won, H. H. Park, Y. J. Kim, S. W. Choi, H. Y. Ha, I.-H. Oh, H. S. Kim, Y. S. Kang, and K. J. Ihn, Macromolecules, 36, 3228 (2003).

(12) J. H. Chen, M. Asano, T. Yamaki, and M. Yoshida, J. Power Source, 158, 69 (2006).

(13) Y. Yin, S. Hayashi, O. Yamada, H. Kita, and K. Okamoto, Macromol. Rapid Commun., 26, 696 (2005).

(14) D. S. Kim, H. B. Park, J. W. Rhim, and Y. M. Lee, Solid State Ionics, 176, 117 (2005).

(15) K. Bouzek, S. Moravcova, Z. Samec, and J. Schauer, J. Electrochem. Soc., 150, E329 (2003).

(16) J. Meier-Haack, A. Taeger, C. Vogel, K. Schlenstedt, W. Lenk, and D. Lehmann, Sep. Pur. Tech., 41, 207 (2005).

(17) A. Taeger, C. Vogel, D. Lehmann, W. Lenk, K. Schlenstedt, 
and J. Meier-Haack, Macromol. Symp., 210, 175 (2004).

(18) A. Taeger, C. Vogel, D. Lehmann, D. Jehnichen, H. Komber, J. Meier-Haack, N. A. Ochoa, S. P. Nunes, and K. V. Peinemann, React. Funct. Polym., 57, 77 (2003).

(19) Y. Chen, D. Liu, Q. Deng, and X. He, J. Polym. Sci. Part A: Polym. Chem., 44, 3434 (2006).

(20) A. Hasneen, S. J. Kim, and H. J. Paik, Macromol. Res., 15, 541 (2007).

(21) J. H. Kim, J. Won, and Y. S. Kang, J. Polym. Sci. Part B:
Polym. Phys., 42, 2263 (2004).

(22) J.-W. Rhim, H. B. Park, C.-S. Lee, J.-H. Jun, D. S. Kim, and Y. M. Lee, J. Membr. Sci., 238, 143 (2004).

(23) J. H. Kim, B. R. Min, K. B. Lee, J. Won, and Y. S. Kang, Chem. Commun., 2732 (2002).

(24) H. S. Huang, C. Y. Chen, S. C. Lo, C. J. Lin, S. J. Chen, and L. J. Lin, Appl. Surf. Sci., 253, 2685 (2006).

(25) J. Ding, C. Chuy, and S. Holdcroft, Chem. Mater., 13, 2231 (2001). 